\title{
Determination of Lead, Cations, and Anions Concentration in Indoor and Outdoor Air at the Primary Schools in Kuala Lumpur
}

\author{
Normah Awang and Farhana Jamaluddin \\ Environmental Health and Industrial Safety Programme, Faculty of Health Sciences, Universiti Kebangsaan Malaysia, \\ Jalan Raja Muda Abdul Aziz, 50300 Kuala Lumpur, Malaysia
}

Correspondence should be addressed to Normah Awang; awang_normah@yahoo.com

Received 13 April 2014; Accepted 13 July 2014; Published 22 July 2014

Academic Editor: Mynepalli K. C. Sridhar

Copyright (C) 2014 N. Awang and F. Jamaluddin. This is an open access article distributed under the Creative Commons Attribution License, which permits unrestricted use, distribution, and reproduction in any medium, provided the original work is properly cited.

\begin{abstract}
This study was carried out to determine the concentration of lead $(\mathrm{Pb})$, anions, and cations at six primary schools located around Kuala Lumpur. Low volume sampler $\left(\right.$ MiniVol $\left.\mathrm{PM}_{10}\right)$ was used to collect the suspended particulates in indoor and outdoor air. Results showed that the concentration of $\mathrm{Pb}$ in indoor air was in the range of $5.18 \pm 1.08 \mu \mathrm{g} / \mathrm{g}-7.01 \pm 0.08 \mu \mathrm{g} / \mathrm{g}$. All the concentrations of $\mathrm{Pb}$ in indoor air were higher than in outdoor air at all sampling stations. The concentrations of cations and anions were higher in outdoor air than in indoor air. The concentration of $\mathrm{Ca}^{2+}(39.51 \pm 5.01 \mathrm{mg} / \mathrm{g}-65.13 \pm 9.42 \mathrm{mg} / \mathrm{g})$ was the highest because the cation existed naturally in soil dusts, while the concentrations of $\mathrm{NO}_{3}{ }^{-}$and $\mathrm{SO}_{4}{ }^{2-}$ were higher in outdoor air because there were more sources of exposure for anions in outdoor air, such as highly congested traffic and motor vehicles emissions. In comparison, the concentration of $\mathrm{NO}_{3}{ }^{-}(29.72 \pm 0.31 \mu \mathrm{g} / \mathrm{g}-32.00 \pm 0.75 \mu \mathrm{g} / \mathrm{g})$ was slightly higher than $\mathrm{SO}_{4}{ }^{2-}$. The concentrations of most of the parameters in this study, such as $\mathrm{Mg}^{2+}, \mathrm{Ca}^{2+}, \mathrm{NO}_{3}{ }^{-}, \mathrm{SO}_{4}{ }^{2-}$, and $\mathrm{Pb}^{2+}$, were higher in outdoor air than in indoor air at all sampling stations.
\end{abstract}

\section{Introduction}

Air pollution is generally the most widespread and obvious kind of environmental damage [1]. Kuala Lumpur, which is the federal capital and the largest city in Malaysia, is also suffering from air pollution problem. The last decade has seen its phenomenal growth as a centre of commerce in the region, and this trend is still continuing. With the increase in energy consumption and urbanization in Kuala Lumpur, the increase in ambient air pollution seems inevitable [2].

Air pollutants, which exist in the form of solid, semisolid, liquid, and gas, are emitted directly or indirectly from their sources. Some heavy metals such as lead and cadmium are common environmental pollutants in industrialised and developing countries [3]. Lead is a very toxic, nondegradable heavy metal that exists naturally in Earth's crust [4, 5]. Lead in the atmosphere arises from two major ways, which are primary sources including lead from mining activities and secondary sources such as industrial emission, battery manufacturing, and additives in motor vehicles gasoline. In any population, children are more vulnerable to lead exposure than adults because children have higher hand-to-mouth activities and higher rate of gastrointestinal absorption, and their developing brains are more sensitive to insults from lead exposure [6].

Ionic species either anions or cations can significantly be found in the form of particulate in the air especially during air pollution. Generally, anions such as sulphate $\left(\mathrm{SO}_{4}{ }^{2-}\right)$ and nitrate $\left(\mathrm{NO}_{3}{ }^{-}\right)$are secondary particulates and usually dominate air pollution. Calcium $\left(\mathrm{Ca}^{2+}\right)$ that arises from soils and magnesium $\left(\mathrm{Mg}^{2+}\right)$ and chloride $\left(\mathrm{Cl}^{-}\right)$that comes from marine sources are some examples of cations [7].

This paper reports the concentration of lead, cations, and anions in air at the primary schools in Kuala Lumpur. Then, the concentrations of the parameters between indoor and outdoor air in every sampling station are compared. 
TABLE 1: List of sampling stations.

\begin{tabular}{lc}
\hline Sampling station & Primary schools \\
\hline A & SK Jalan Raja Muda Abdul Aziz \\
B & SK (L) Jalan Batu \\
C & SK Jalan Hang Tuah 1 dan 2 \\
D & SK St. John 1 dan 2 \\
E & SK (P) Pudu 1 dan 2 \\
F & SK Convent Sentul 1 dan 2 \\
\hline
\end{tabular}

\section{Methodology}

2.1. Study Area. This study was conducted in Kuala Lumpur, which is a city characterised with highly congested traffic city. Six sampling points were chosen by using stratified random sampling, and size for known population was calculated. Table 1 shows the list of the sampling stations.

2.2. Sampling and Analysis. Suspended particulate for indoor and outdoor air was sampled using low volume sampler $\left(\mathrm{MiniVol} \mathrm{PM}_{10}\right)$ for $24 \mathrm{~h}$ with fibre glass filter papers pore size $0.45 \mu \mathrm{m}$ and diameter $47 \mathrm{~mm}$. The filter papers were then split into two parts. The first half was used for analysis of anions and cations, whilst the second half was used for analysis of lead. For lead concentration determination, a part of the filter paper was added with nitric acid and perchloric acid in the ratio of $16: 4$. Then, the mixture was filtered using vacuum pump with cellulose acetate filter papers (pore size $0.2 \mu \mathrm{m}$ ), and $50 \mathrm{~mL}$ of deionised water was added. Lead concentration in the samples was determined using Inductively Coupled Plasma Mass Spectrophotometry (ICP-MS).

For anions and cations analysis, the second part of the filter paper was added with $40 \mathrm{~mL}$ of deionised water into centrifuge tube. Centrifugation was done for $45 \mathrm{~min}$ at $1500 \mathrm{rpm}$. Then, the mixture was filtered using vacuum pump and $100 \mathrm{~mL}$ of deionised water was added. All the samples were placed in polyethylene bottles at $4^{\circ} \mathrm{C}$. The concentration of cations $\left(\mathrm{Mg}^{2+}, \mathrm{Ca}^{2+}\right.$, and $\left.\mathrm{K}^{+}\right)$was analysed using Atomic Absorption Spectroscopy, while the concentration of anions $\left(\mathrm{NO}_{3}{ }^{-}\right.$and $\left.\mathrm{SO}_{4}{ }^{2-}\right)$ was determined using HACH DR 2800 spectrophotometer. The data were then analysed using Statistical Package for the Social Sciences (SPSS) software version 16.

\section{Results and Discussion}

3.1. Concentration of Lead for Indoor and Outdoor Air. Overall, this study indicated that lead concentration was higher for indoor air than outdoor air. For indoor air, the lead concentrations were in the range of $5.18 \pm 1.08 \mu \mathrm{g} / \mathrm{g}-$ $7.01 \pm 0.08 \mu \mathrm{g} / \mathrm{g}$. For outdoor air, the lead concentrations were in the range of $3.25 \pm 0.35 \mu \mathrm{g} / \mathrm{g}-4.09 \pm 0.71 \mu \mathrm{g} / \mathrm{g}$ (see Table 2). Based on one-way ANOVA test, there was a significant difference $(P<0.05)$ for the lead concentrations in indoor air. Station $\mathrm{F}$ showed the highest lead concentration for indoor air as the classroom was near the main road, which was highly congested during peak hours. Shen et al. [4] and
TABLE 2: Concentration of $\mathrm{Pb}$ for both indoor and outdoor air according to sampling stations.

\begin{tabular}{|c|c|c|}
\hline \multirow{2}{*}{ Sampling station } & \multicolumn{2}{|c|}{ Concentration of $\mathrm{Pb}(\mu \mathrm{g} / \mathrm{g})$} \\
\hline & Indoor air & Outdoor air \\
\hline A & $6.05 \pm 1.14$ & $3.90 \pm 1.04$ \\
\hline B & $6.01 \pm 0.62$ & $3.25 \pm 0.35$ \\
\hline $\mathrm{C}$ & $7.01 \pm 0.08$ & $3.53 \pm 0.05$ \\
\hline $\mathrm{D}$ & $5.64 \pm 0.09$ & $4.09 \pm 0.71$ \\
\hline $\mathrm{E}$ & $5.18 \pm 1.08$ & $3.33 \pm 0.08$ \\
\hline $\mathrm{F}$ & $8.15 \pm 0.52$ & $3.99 \pm 1.15$ \\
\hline
\end{tabular}

Mohamed et al. [8] state that stationeries, desk paint, and coloured book wrappers contribute to lead in indoor air.

3.2. Concentration of Cations in Indoor and Outdoor Air. The concentration of $\mathrm{Mg}^{2+}$ in indoor air was in the range of 1.83$3.87 \mathrm{mg} / \mathrm{g}$, while the concentration of $\mathrm{Mg}^{2+}$ in outdoor air was $2.63-4.41 \mathrm{mg} / \mathrm{g}$ (see Table 3). The concentration of $\mathrm{Mg}^{2+}$ was the lowest compared to other cations. $\mathrm{Mg}^{2+}$ is one of the components with high concentration in sea spray aerosol, which was far from sampling points. Next, for $\mathrm{Ca}^{2+}$, the range of concentration was quite high, $30.30 \pm 2.09 \mathrm{mg} / \mathrm{g}-48.33 \pm$ $1.97 \mathrm{mg} / \mathrm{g}$ in indoor air, while the range of concentration for outdoor air was $39.51 \pm 5.01 \mathrm{mg} / \mathrm{g}-65.13 \pm 9.42 \mathrm{mg} / \mathrm{g}$ (see Table 3).

This finding could be because the cation exists naturally in soils and Earth's crust; thus it has higher concentration in indoor air than outdoor air. Station A showed the highest concentration of $\mathrm{Ca}^{2+}$ in outdoor air. The indoor $\mathrm{Ca}^{2+}$ could probably come from soil dust introduced into the indoor environment. This finding was due to the construction project located in the school compound. There was a significant difference in $\mathrm{Ca}^{2+}$ concentrations for both indoor and outdoor air based on the statistical results. The concentration of $\mathrm{K}^{+}$for indoor air was in the range of $38.07 \pm 1.03-60.56 \pm$ $3.71 \mathrm{mg} / \mathrm{g}$, while the concentration of $\mathrm{K}^{+}$for outdoor air was in the range of $37.64 \pm 5.33 \mathrm{mg} / \mathrm{g}-66.33 \pm 7.54 \mathrm{mg} / \mathrm{g}$ (see Table 3). Statistical results showed that the significant difference in the concentration of $\mathrm{K}^{+}$was only in outdoor air. $\mathrm{K}^{+}$is a mineral found in Earth's crust. The mineral is transferred from rocks to soil [9].

3.3. Concentration of Anions in Indoor and Outdoor Air. The concentration of $\mathrm{SO}_{4}{ }^{2-}$ in indoor air at every sampling point was in the range of $21.76 \pm 1.13 \mu \mathrm{g} / \mathrm{g}-23.42 \pm 0.91 \mu \mathrm{g} / \mathrm{g}$, while the concentration of $\mathrm{SO}_{4}{ }^{2-}$ in outdoor air was in the range of $22.89 \pm 2.04 \mu \mathrm{g} / \mathrm{g}-23.95 \pm 0.92 \mu \mathrm{g} / \mathrm{g}$ (see Table 4 ). The concentration of ion $\mathrm{SO}_{4}{ }^{2-}$ was high in outdoor air due to the emission from motor vehicles in the heavy traffic nearby the schools. Emission of anthropogenic pollutants such as sulphur dioxide, vehicles exhaust, and natural emission from decaying plants and animals may increase the concentration of $\mathrm{SO}_{4}{ }^{2-}$ in the air [10]. The concentration of $\mathrm{NO}_{3}{ }^{-}$in indoor air was in the range of $21.34 \pm 0.97 \mu \mathrm{g} / \mathrm{g}-24.80 \pm 0.58 \mu \mathrm{g} / \mathrm{g}$, while the concentration of $\mathrm{NO}_{3}{ }^{-}$in outdoor air was in the 
TABLE 3: Concentration of $\mathrm{Mg}^{2+}, \mathrm{Ca}^{2+}$, and $\mathrm{K}^{+}$for both indoor and outdoor air according to sampling stations.

\begin{tabular}{lcccccc}
\hline \multirow{2}{*}{ Sampling station } & \multicolumn{2}{c}{$\mathrm{Mg}^{2+}(\mathrm{mg} / \mathrm{g})$} & \multicolumn{2}{c}{$\mathrm{Ca}^{2+}(\mathrm{mg} / \mathrm{g})$} & \multicolumn{2}{c}{$\mathrm{K}^{+}(\mathrm{mg} / \mathrm{g})$} \\
& Indoor & Outdoor & Indoor & Outdoor & Indoor & Outdoor \\
\hline A & $3.87 \pm 0.05$ & $4.41 \pm 1.07$ & $47.65 \pm 2.12$ & $65.13 \pm 9.42$ & $60.56 \pm 3.71$ & $61.69 \pm 5.24$ \\
B & $3.06 \pm 0.18$ & $3.28 \pm 1.54$ & $48.33 \pm 1.97$ & $61.49 \pm 9.67$ & $38.07 \pm 1.03$ & $37.64 \pm 5.33$ \\
C & $2.59 \pm 0.99$ & $3.23 \pm 1.89$ & $38.85 \pm 0.72$ & $56.03 \pm 9.72$ & $52.80 \pm 1.41$ & $66.33 \pm 7.54$ \\
D & $2.64 \pm 0.87$ & $3.03 \pm 0.74$ & $36.92 \pm 1.56$ & $52.34 \pm 7.16$ & $45.09 \pm 1.09$ & $64.25 \pm 4.92$ \\
E & $1.83 \pm 0.39$ & $2.81 \pm 1.93$ & $40.8 \pm 0.53$ & $60.56 \pm 4.93$ & $48.74 \pm 1.34$ & $50.16 \pm 4.36$ \\
F & $1.88 \pm 0.11$ & $2.63 \pm 0.12$ & $30.30 \pm 2.09$ & $39.51 \pm 5.01$ & $58.23 \pm 0.97$ & $49.28 \pm 5.05$ \\
\hline
\end{tabular}

TABLE 4: Concentration of $\mathrm{SO}_{4}{ }^{2-}$ and $\mathrm{NO}^{3-}$ for both indoor and outdoor air according to sampling stations.

\begin{tabular}{lcccr}
\hline Sampling station & \multicolumn{2}{c}{$\mathrm{SO}_{4}{ }^{2-}(\mathrm{mg} / \mathrm{g})$} & \multicolumn{2}{c}{$\mathrm{NO}^{3-}(\mathrm{mg} / \mathrm{g})$} \\
\hline $\mathrm{A}$ & Indoor & Outdoor & Indoor & $31.10 \pm 0.08$ \\
$\mathrm{~B}$ & $21.76 \pm 1.13$ & $22.89 \pm 2.04$ & $25.36 \pm 0.76$ & $32.00 \pm 0.75$ \\
$\mathrm{C}$ & $22.81 \pm 0.55$ & $23.09 \pm 1.35$ & $23.17 \pm 1.56$ & $30.93 \pm 0.41$ \\
$\mathrm{D}$ & $23.42 \pm 1.91$ & $23.95 \pm 2.51$ & $22.79 \pm 0.38$ & $30.72 \pm 0.26$ \\
$\mathrm{E}$ & $23.05 \pm 2.43$ & $23.38 \pm 2.74$ & $24.80 \pm 1.21$ & $29.53 \pm 0.63$ \\
$\mathrm{~F}$ & $22.76 \pm 1.81$ & $23.73 \pm 1.21$ & $21.34 \pm 0.97$ & $29.72 \pm 0.31$ \\
\hline
\end{tabular}

range of $29.72 \pm 0.31 \mu \mathrm{g} / \mathrm{g}-32.00 \pm 0.75 \mu \mathrm{g} / \mathrm{g}$ (see Table 4$)$. Overall, the concentration of $\mathrm{NO}_{3}{ }^{-}$was found higher in outdoor air than in indoor air. Fuels and exhaust emission from motor vehicles were the main sources for the anions in the air.

\section{Conclusion}

Concentration of lead for both indoor and outdoor air at the sampling stations did not exceed the $1.5 \mu \mathrm{g} / \mathrm{m}^{3}$ standard given by the Department of Environment. But the level of the contaminants must be monitored from time to time because exposure to the high concentration of lead can cause chronic health effects. All the sampling stations showed concentration of cations and anions higher in outdoor air than indoor air. This finding could be because the outdoor environment was exposed to higher sources of these cations and anions. Relative concentration for cations in this study was $\mathrm{Ca}^{2+}>$ $\mathrm{K}^{+}>\mathrm{Mg}^{2+}$, while for anions it was $\mathrm{NO}_{3}{ }^{-}>\mathrm{SO}_{4}{ }^{2-}$.

\section{Conflict of Interests}

The authors declare that there is no conflict of interests regarding the publication of this paper.

\section{Acknowledgments}

The authors would like to thank their research assistant from the Department of Environmental Science, Faculty of Science and Technology, Universiti Kebangsaan Malaysia. Laboratory assistants from the Faculty of Science and Technology and Faculty of Health Sciences are also gratefully acknowledged.

\section{References}

[1] W. P. Cunningham, M. A. Cunningham, and B. W. Saigo, Environmental Science: A Global Concern, McGraw-Hill, New York, NY, USA, 9th edition, 2005.

[2] B. Chen, C. Hong, and H. Kan, "Exposures and health outcomes from outdoor air pollutants in China," Toxicology, vol. 198, no. 1-3, pp. 291-300, 2004.

[3] J. Hogervorst, M. Plusquin, J. Vangronsveld et al., "House dust as possible route of environmental exposure to cadmium and lead in the adult general population," Environmental Research, vol. 103, no. 1, pp. 30-37, 2007.

[4] X. Shen, J. F. Rosen, D. Guo, and S. Wu, "Childhood lead poisoning in China," The Science of the Total Environment, vol. 181, no. 2, pp. 101-109, 1996.

[5] S. T. Y. Tong and K. C. Lam, "Home sweet home? A case study of household dust contamination in Hong Kong," Science of the Total Environment, vol. 256, no. 2-3, pp. 115-123, 2000.

[6] M. M. Kadir, N. Z. Janjua, S. Kristensen, Z. Fatmi, and N. Sathiakumar, "Status of children's blood lead levels in Pakistan: implications for research and policy," Public Health, vol. 122, no. 7, pp. 708-715, 2008.

[7] R. Tsitouridou, D. Voutsa, and T. Kouimtzis, "Ionic composition of PM10 in the area of Thessaloniki, Greece," Chemosphere, vol. 52, no. 5, pp. 883-891, 2003.

[8] N. Mohamed, R. Ishak, R. Rahmat, and D. Abdul Rahim, "A study of lead levels in stationeries available in the market," NCD Malaysia, vol. 3, no. 3, pp. 2-5, 2004.

[9] J. Lim, L. D. Sabin, K. C. Schiff, and K. D. Stolzenbach, "Concentration, size distribution, and dry deposition rate of particleassociated metals in the Los Angeles region," Atmospheric Environment, vol. 40, no. 40, pp. 7810-7823, 2006.

[10] V. Ariola, A. D’Alessandro, F. Lucarelli et al., "Elemental characterization of PM10, PM2.5 and PM1 in the town of Genoa, Italy," Chemosphere, vol. 62, no. 2, pp. 226-232, 2006. 


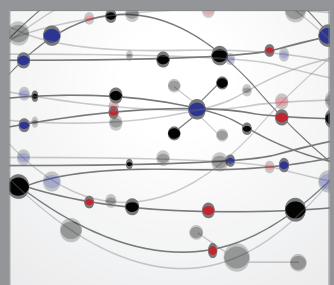

The Scientific World Journal
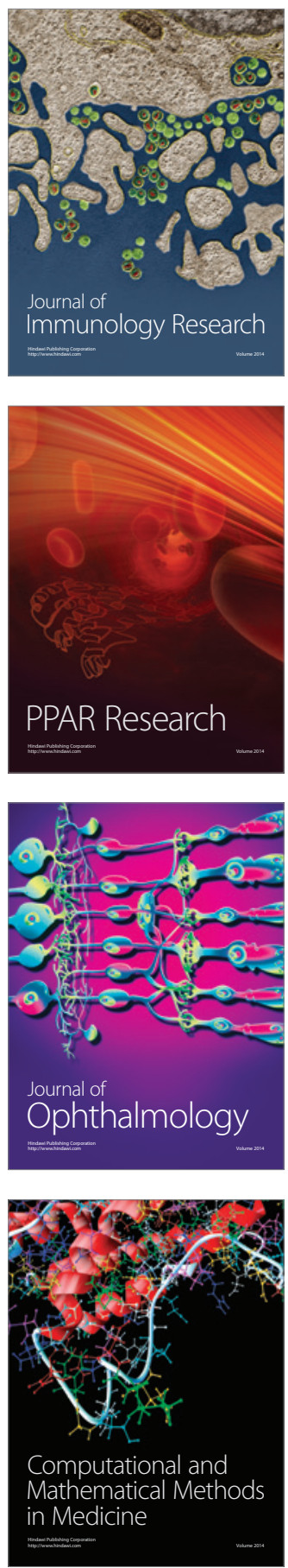

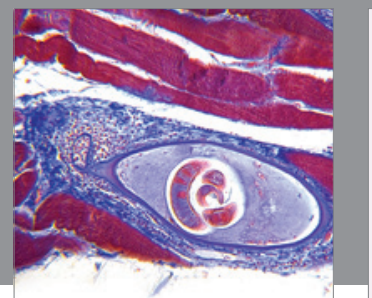

Gastroenterology

Research and Practice
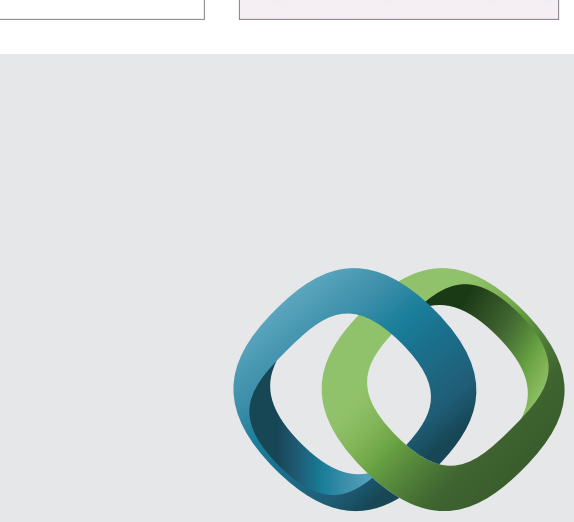

\section{Hindawi}

Submit your manuscripts at

http://www.hindawi.com
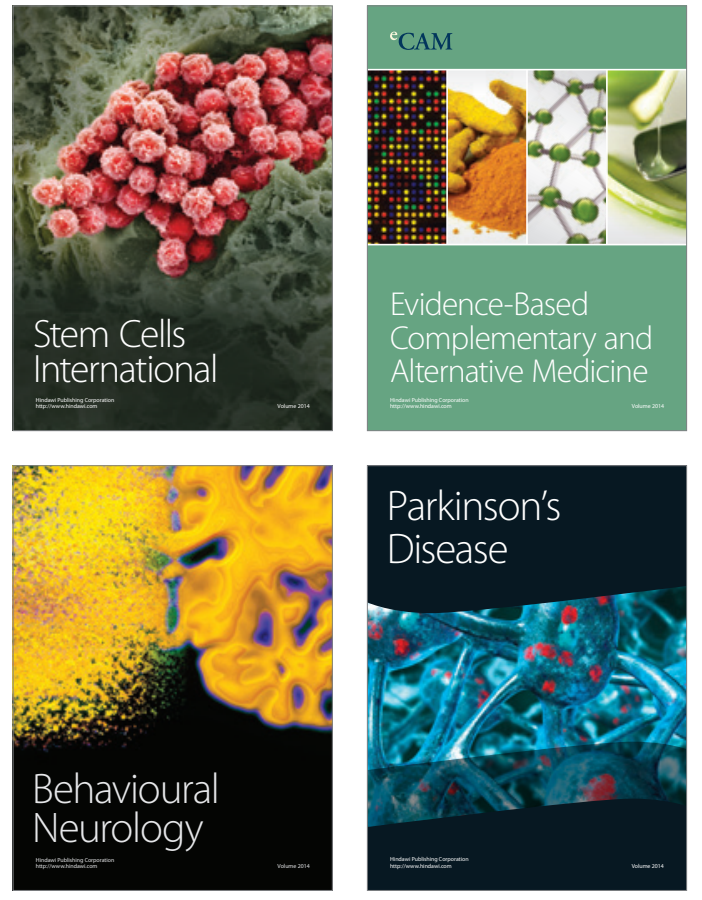
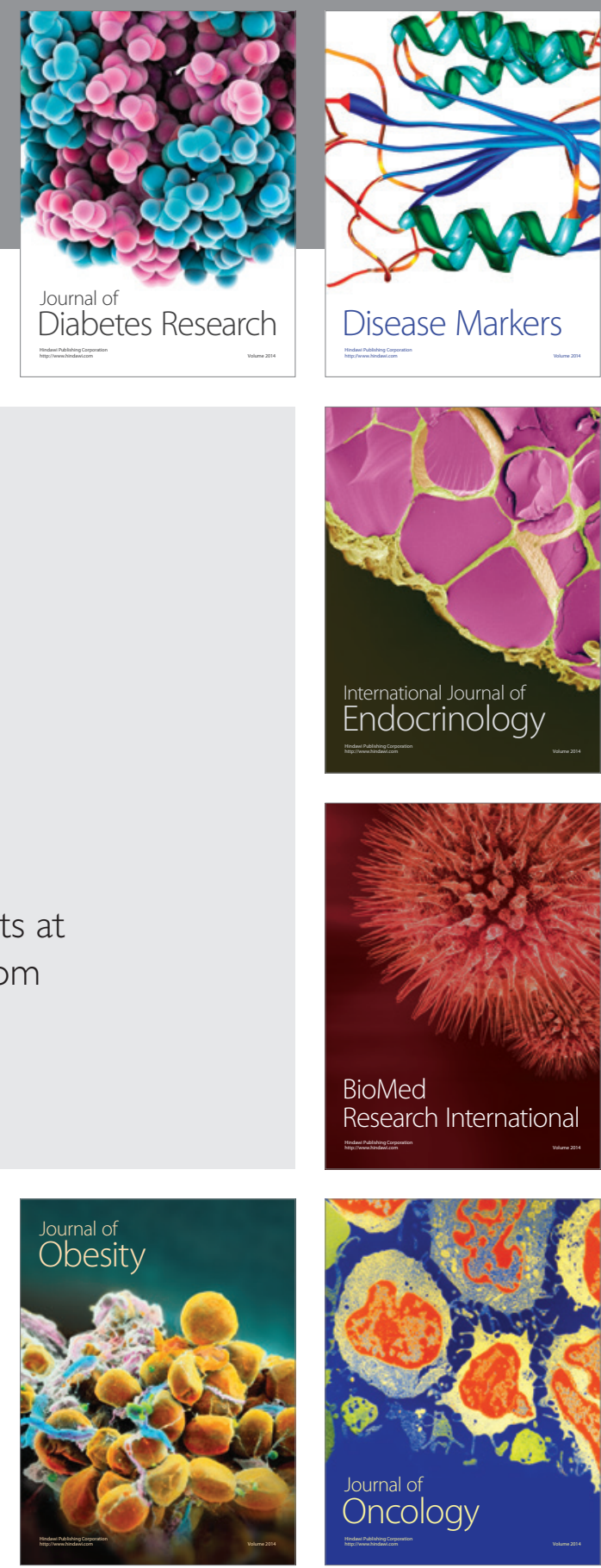

Disease Markers
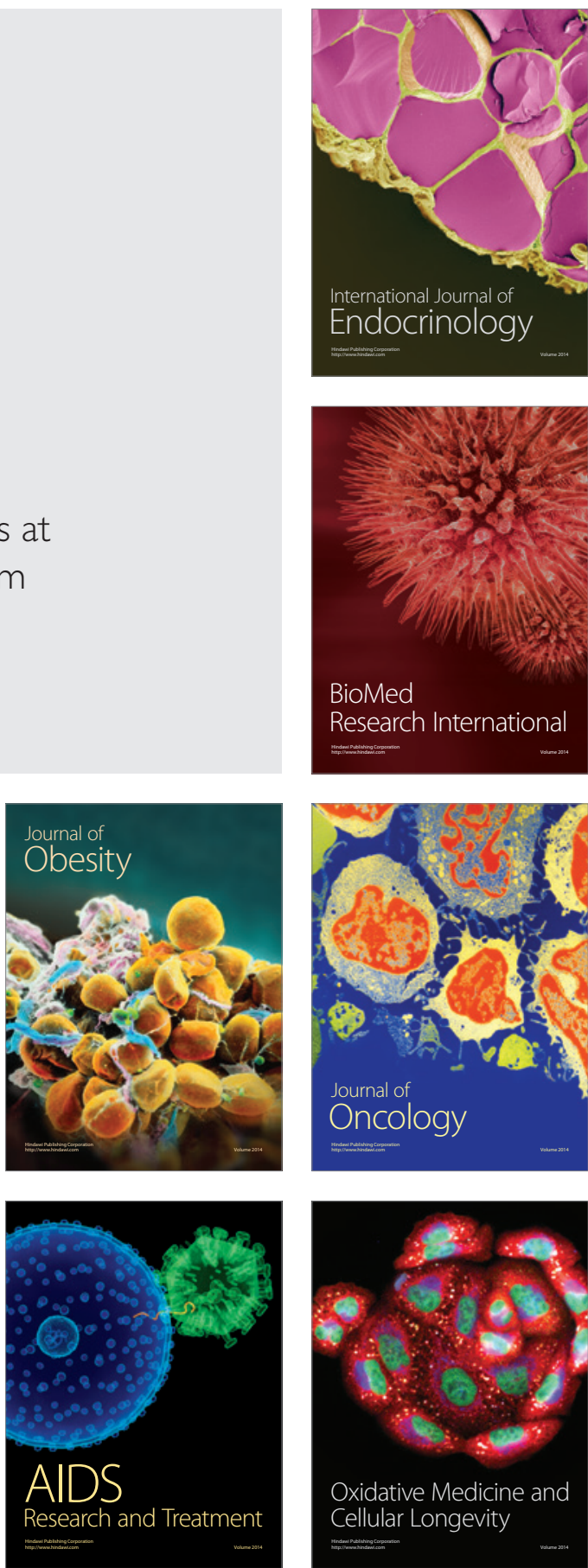